\title{
Evaluation of the clinical and analgesic effects of subarachnoid ketamine-lidocaine administration in goats undergoing mastectomy
}

This article was published in the following Dove Press journal:

Veterinary Medicine: Research and Reports

12 May 2014

Number of times this article has been viewed

\author{
Mousa Daradka \\ Zuhair Bani Ismail \\ Department of Veterinary Clinical \\ Sciences, Faculty of Veterinary \\ Medicine, Jordan University of Science \\ and Technology, Irbid, Jordan
}

\begin{abstract}
Twenty adult female goats affected with chronic mastitis were subjected to mastectomy or hemimastectomy under subarachnoid regional analgesia using a ketaminelidocaine combination. Ketamine at $1.5 \mathrm{mg} / \mathrm{kg}$ and lidocaine hydrochloride at $1.25 \mathrm{mg} / \mathrm{kg}$ were administered intrathecally at the lumbosacral intervertebral space. Goats were then subjected to a 120-minute observation period for systemic or neurotoxic symptoms such as agitation, restlessness, hind limb paralysis, or seizures. In addition, analgesia of the caudal abdominal region and signs of systemic sedation were scored on a scale of $0-3$. Heart rate, respiratory rate, and rectal temperature were also recorded prior to (baseline values) and at 5, 15, 30, 60, 90, and 120 minutes after administration. Mastectomy or hemimastectomy operation was carried out after full assurance of the analgesic effect on the udder and caudal abdominal region. Time of onset of surgical analgesia (score 3) was achieved at 15 minutes and lasted for 60 minutes. Maximal sedation score was recorded at 15 minutes and lasted for 60 minutes, then decreased thereafter, with the lowest sedation score recorded at 120 minutes. There was a significant $(P<0.05)$ rise in heart rate at some point between 5-90 minutes, while the respiratory rate and rectal temperature did not change significantly from baseline values. Postoperatively, animals did not show any signs of pain or discomfort. Follow-up on the operated goats showed that all wounds were fully healed without any significant complications. In goats, intrathecal administration of ketaminelidocaine combination resulted in a safe and effective analgesia of the caudal abdominal and udder region sufficient to perform mastectomy or hemimastectomy.
\end{abstract}

Keywords: analgesia, sedation, ruminants, mastectomy

\section{Introduction}

In the field, general anesthesia in small ruminants is challenging. ${ }^{1-3}$ Standing surgery under regional analgesia achieved by lumbar epidural or lumbar subarachnoid is used frequently in ruminants. ${ }^{2,3}$ Surgical operations carried out under such methods of local analgesia include various obstetrical interferences, docking, mastectomy, and surgeries of the anus, rectum, and vagina. ${ }^{4}$ Local anesthetics such as lidocaine hydrochloride, sedatives such as xylazine, and opioids such as butorphanol or their combinations have been used for epidural analgesia in ruminants. ${ }^{2,3,5-7}$ In addition, subarachnoid ketamine injection has been advocated for surgeries involving the hind legs, perineum, vulva, and rectum in small ruminants. ${ }^{7,8}$

A combination of drugs for the induction of analgesia is usually advantageous over the administration of a single drug. ${ }^{6}$ Ketamine has been used in combinations with a variety of sedatives or local anesthetics. ${ }^{2,3,5-9}$ Combination of ketamine with either xylazine or medetomidine produces analgesia of the hindquarters for 45-60
Correspondence: Mousa Daradka Department of Veterinary Clinical Sciences, Faculty of Veterinary Medicine, Jordan University of Science and Technology, PO Box 3030, Irbid 221 10, Jordan

Tel +962796607092

Fax +962270201081

Email daradka@just.edu.jo
Veterinary Medicine: Research and Reports 2014:5 35-39 (c) (i) (5) 2014 Daradka and Ismail. This work is published by Dove Medical Press Limited, and licensed under Creative Commons Attribution - Non Commercial (unported, v3.0) License. The full terms of the License are available at http://creativecommons.org/licenses//by-nc/3.0/. Non-commercial uses of the work are permitted without any further hew to how to request permission may be found at: http://www.dovepress.com/permissions.php 
minutes. $^{7}$ The analgesic effects of romifidine and ketamine, have been described in goats. ${ }^{9}$ Combined subarachnoid administration of ketamine and lidocaine in goats resulted in a longer duration of anesthesia than administration of each drug separately. ${ }^{10}$

Mastectomy or hemimastectomy are indicated as a last resort treatment option for gangrenous mastitis, chronic suppurative mastitis, pendulous udder, chronic obstructive mastitis, and irreparable udder injuries in goats. ${ }^{11-14}$ The surgery is radical, and general anesthesia is required in most cases. However, local or regional anesthesia may be used. To our knowledge, there are no reports in the recent literature on the use of intrathecal ketamine-lidocaine combination in goats undergoing mastectomy. Therefore, the aim of this study was to evaluate the safety and efficiency of intrathecal administration of ketamine-lidocaine in goats undergoing mastectomy and hemimastectomy.

\section{Materials and methods Animals}

Twenty adult mixed-breed female goats, aged 1-2 years and weighing 30-60 kg, were included in this experiment. Goats were presented to the Veterinary Health Center at Jordan University of Science and Technology during the period 2006-2010 for evaluation of various mammary gland disorders (udder trauma, suppurative mastitis, and pendulous udder). Goats were included in the study only if mastectomy or hemimastectomy was suggested to the owner as a treatment. Experimental protocol was approved by the Animal Care and Use Committee at Jordan University of Science and Technology. Written consents for the surgery and publication were obtained from all animal owners.

\section{Animal preparation for anesthesia}

The animals were taken to the operation room 20 minutes prior to the surgery. Animals were not administered any premedication drugs for restraint prior to the intrathecal administration of the test drug combination. Animals were placed under minimal restraint in a standing position in preparation for drug administration. The lumbosacral area was clipped and the skin prepared for aseptic placement of an $18 \mathrm{~g}, 3.5$ inch spinal needle (Spinocan; B. Braun Melsungen AG, Melsungen, Germany) into the subarachnoid space as described previously. ${ }^{7}$ Correct needle placement was ensured by free flow of cerebrospinal fluid from the hub. At this time, ketamine-lidocaine was administered at a dose of $1.5 \mathrm{mg} / \mathrm{kg}$ ketamine (Alfasan International, Woerden, Holland) and $1.25 \mathrm{mg} / \mathrm{kg}$ of $2 \%$ lidocaine (free of adrenaline) (BDI Pharma, Columbia, SC, USA). ${ }^{10}$

\section{Vital signs, analgesia, and sedation scoring}

Heart rate (HR), respiratory rate (RR), rectal temperature (RT), analgesia, and sedation were assessed prior to (baseline data) and at 5, 10, 15, 30, 60, 90, and 120 minutes after administration of drugs. HR and RR were recorded with a stethoscope; RT was taken by a digital thermometer.

Analgesia was detected on both sides of the udder using a pin prick test. Analgesia was determined by lack of sensory perception, and the degree of analgesia was given a score of 0 to $3 .{ }^{7}$ A score of 0 (strong reaction) was given if there was strong reaction to the pin prick test. A score of 1 (weak reaction) was given if there was a mild and simultaneous reaction to the pin prick test. A score of 2 (moderate reaction) was given if there was moderate but not consistent reaction to the pin prick test. A score of 3 was given if there was no reaction to the pin prick test. The degree of sedation was determined using a scoring scale of 0 to $3 .^{7}$ A score of 0 (no sedation) was given if the animal was aware of its surroundings and resisted restraint. A score of 1 (mild sedation) was given if the animal attempted to raise its head, move its forelimbs, and had a closed mouth and open eyes. A score of 2 (moderate sedation) was given if the animal relaxed on the table, moved forelimbs, and had a closed mouth and open eyes. A score of 3 (severe sedation) was given if the animal relaxed on the table with extended neck and closed eyes.

\section{Surgical technique}

After achieving surgical plane of analgesia (score 3), mastectomy was performed as described previously. ${ }^{12,14}$ Briefly, an elliptical skin incision either around the base of the udder in cases of mastectomy or around the base of the selected half in case of hemimastectomy (Figure 1) was made. Sufficient skin flap was left to primarily close the surgical area after udder removal. The area was bluntly dissected and the skin was reflected dorsally away from the
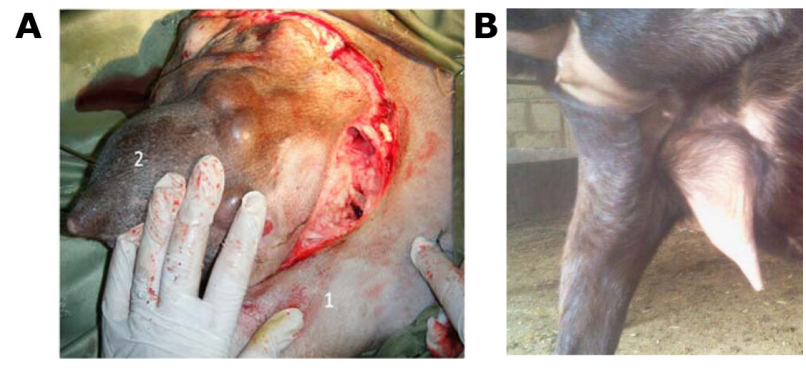

Figure I Photograph of a goat showing the surgical incision used for hemimastectomy.

Notes: (A) The normal udder half (I) and the affected udder half (2). Healed hemimastectomy incision in a goat $(\mathbf{B})$ 
glandular tissue. The main blood vessels (superficial caudal epigastric vein and external pudendal and perineal arteries) were located, ligated with transfixing ligation using size 0 absorbable suture material (Monocryl, Ethicon, Somerville, NJ, USA), then severed. The mammary tissue was separated from the abdominal tunic and the suspensory ligament severed. The glandular tissues were removed, and the mammary gland lymph node was dissected. In cases of hemimastectomy, connecting blood vessels between the udder halves were ligated and the median or suspensory udder ligament was preserved. The subcutaneous fascia was closed using size 1 absorbable suture material (Monocryl; Ethicon) in a simple continuous pattern. Skin was closed using size 1 nonabsorbable suture material (Ethilon; Ethicon) in a simple interrupted pattern.

\section{Postoperative care}

The goat's general condition and surgical site were evaluated twice daily for 5 days, then once daily until wound healing. Perioperative antibiotics were administered to all goats 2 hours prior to surgery. Penicillin-streptomycin at a dose of $20 \mathrm{mg} / \mathrm{kg}$ for the procaine penicillin and $25 \mathrm{mg} / \mathrm{kg}$ for the dihydrostreptomycin (Pen and Strep, Norbrook Laboratories, Newry, Northern Ireland), and flunixin meglumine (Finadyne, Schering-Plough, Kenilworth, New Jersey, USA) at a dose of $1.1 \mathrm{mg} / \mathrm{kg}$ were administered intravenously once daily for 5 days.

\section{Statistical methods}

Data was analyzed using the SPSS software version 10.0 computer program (SPSS Inc., Chicago, IL, USA). Repeated measures analysis of variance was used to test the effect of drug administration on HR, RR, and RT, with time as a factor. For analgesia and sedation scores, the nonparametric Kruskal-Wallis $\mathrm{H}$ test was used, followed by a MannWhitney $U$ test with time 0 being considered as baseline.
Differences were considered significant if $P<0.05$. Data were presented as median \pm standard error.

\section{Results}

The maximal analgesia score (score 3) was recorded at 15 minutes after injection and was maintained for 60 minutes. Then analgesia began to decrease until the end of the observation period, but it was higher than the baseline value (Figure 2).

Intrathecal administration of ketamine-lidocaine resulted in moderate to severe sedation. Maximal sedation score (score 3) was recorded at 15 minutes after injection and was maintained for 60 minutes. Then sedation gradually decreased to a mild degree (score 1) at the end of the observation period (Figure 2).

Loss of hind limb muscle tone, control of semiflexed stifle and hock joints, and buckling of pelvic limbs were observed soon after injection. Then all goats had ataxia and subsequent sternal recumbency and remained the same even after the end of the surgery (45-60 minutes). Full recovery of hindquarter muscle tone was achieved at 100-120 minutes after injection.

RR and RT did not change significantly from baseline values after injection throughout the observation period (data not shown). However, intrathecal injection of ketaminelidocaine induced a significant increase $(P<0.05)$ in $\mathrm{HR}$ at 5-90 minutes (Figure 3).

Mastectomy or hemimastectomy was performed successfully under regional spinal analgesia using this anesthesia combination. Animals did not show any sign of pain or discomfort during surgery or recovery. There were no long-lasting hind limb paralysis or weakness, and all goats were able to stand and walk without assistance following recovery from anesthesia. All surgical wounds were fully healed without any significant complications (Figure 1).
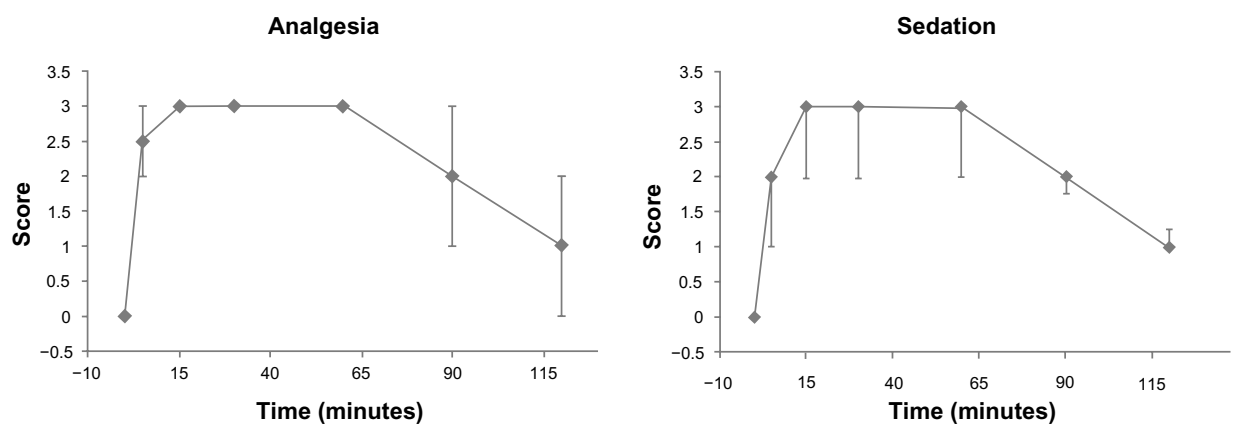

Figure 2 Analgesia and sedation scores (median \pm standard error) of the hindquarters in goats following subarachnoid administration of ketamine-lidocaine ( $\mathrm{n}=20$ ). 


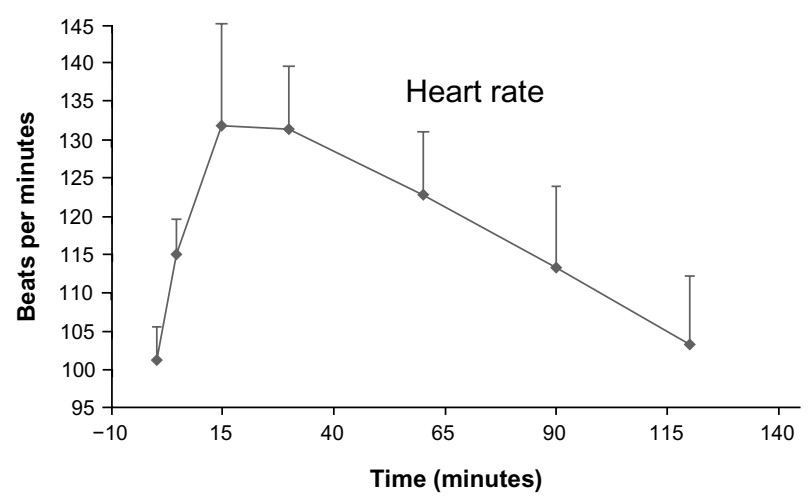

Figure 3 Heart rate (median \pm standard error) in goats having subarachnoid injection of ketamine-lidocaine and mastectomy.

\section{Discussion}

The combination of ketamine and lidocaine $(1.5 \mathrm{mg} / \mathrm{kg}$ and $1.25 \mathrm{mg} / \mathrm{kg}$, respectively) produced analgesia which was sufficient to perform mastectomy and hemimastectomy in goats. The combination had a fast onset of action and long duration of analgesia and sedation. In the present study, the quality of analgesia and degree of sedation after intrathecal injection of ketamine-lidocaine agreed with the results of previous studies. ${ }^{6,9,10}$ Sedation might be due to the slow systemic absorption of ketamine and/or lidocaine from the subarachnoid space. ${ }^{10}$ However, the animals in the latter study did not undergo any surgical procedure, and to our knowledge, this is the first study to utilize such a regime to perform mastectomy. The duration of hindquarter analgesia in this study is comparable to that reported after subarachnoid ketamine-lidocaine injection in goats $(127 \pm 30$ minutes $) .{ }^{10}$ However, the analgesia period was longer than that reported with the use of lidocaine alone ( $66 \pm 31$ minutes) or ketamine alone (49 \pm 13 minutes),${ }^{10}$ or a combination of xylazine and ketamine (15-20 minutes). ${ }^{5}$

Under field conditions, mastectomy can be performed after premedication with sedatives such as xylazine and local infiltration of anesthetics. ${ }^{14}$ Although the intramuscular or intravenous xylazine administration is a convenient method in small ruminants, it may have a compromising effect on the cardiopulmonary system. In contrast, intrathecal ketamine-lidocaine induced analgesia and sedation without any apparent side effects on cardiopulmonary function. HR was increased significantly after ketamine-lidocaine injection, but it remained within normal range for goats (70 to $150 \mathrm{bpm}) .{ }^{15}$ The effect of subarachnoid ketamine injection on HR was reported in several previous studies with inconsistent findings. It has been reported that ketamine administered spinally produced a significant increase in $\mathrm{HR},{ }^{7}$ while others did not find any significant changes. ${ }^{5,6,10}$ It is known, however, that ketamine is a cardiovascular stimulant, so intramuscular or intravenous administration of ketamine causes an increase in HR and blood pressure. ${ }^{16,17}$

In this study, intrathecal injection of ketamine-lidocaine did not induce significant changes in RR and RT. This is in accordance with previous results. ${ }^{710} \mathrm{~A}$ decrease in rectal temperature after the subarachnoid administration of anesthetics was reported in earlier studies in goats. ${ }^{5}$ In later studies, however, ketamine alone did not cause any decrease in RT. When ketamine was combined with xylazine or medetomidine, the decrease in RT persisted for up to 120 minutes. ${ }^{7,10}$

In this study, a small volume of ketamine-lidocaine combination induced complete analgesia of the surgical site. In sheep and goats, $2.5 \mathrm{mg} / \mathrm{kg}$ of lidocaine has been recommended for subarachnoid analgesia. It has been stated that high doses of lidocaine $(5.8 \mathrm{mg} / \mathrm{kg}$ intravenously) are toxic to the central nervous system in sheep. ${ }^{18}$ Also, high concentrations of lidocaine administered epidurally or intrathecally may induce temporary or irreversible trauma to the nervous tissue. ${ }^{18,19}$ In the present study, the dose was reduced to $1.25 \mathrm{mg} / \mathrm{kg}$ to minimize chances of neurotoxicity.

Recovery from subarachnoid anesthesia was uneventful. Although motor function was not assessed during this study, as goats were restrained, some goats were recumbent or ataxic when the surgeries were concluded within 60 minutes. Nonetheless, all goats were able to stand and walk at 100-120 minutes following injection. Animals did not show any signs of pain or discomfort, nor did they show any signs of long-lasting hind limb paralysis or weakness. Intrathecal administration of ketamine-lidocaine may have had some role in reducing postoperative pain. It has been reported that ketamine can be used both epidurally and intrathecally to reduce postoperative pain, with varying degrees of success. ${ }^{20,21}$ Further studies are needed to assess the role of intrathecal administration of ketamine-lidocaine in pain control in animals undergoing prolonged surgeries and to identify possible effects of the combination on blood pressure and oxygen saturation of peripheral blood.

\section{Acknowledgments}

This project was partially sponsored by the Deanship of Research at Jordan University of Science and Technology. The authors would like thank all colleagues of the Veterinary Faculty at Jordan University of Science and Technology for their support.

\section{Disclosure}

The authors report no conflicts of interest in this work. 


\section{References}

1. Hall LW, Clarke KW, Trim CM. Veterinary Anesthesia. 10th ed. London: Harcourt Publishers, WB Saunders; 2011.

2. Lucky NS, Hashim MA, Ahmad JU, Sarker K, Gazi NM, Ahmed S. Caudal epidural analgesia in sheep by using lignocaine hydrochloride and bupivacaine hydrochloride. Bangladesh J Vet Med. 2007;5(1\&2): $77-80$.

3. Tranquilli WJ, Thurmon JC, Grimm KA. Lumb and Jones' Veterinary Anesthesia and Analgesia. $4^{\text {th }}$ ed. Wiley-Blackwell. USA; 2007.

4. DeRossi R, Carneiro RPB, Ossuna MR, et al. Sub-arachnoid ketamine administration combined with or without misoprostol/oxytocin to facilitate cervical dilation in ewes: a case study. Small Ruminant Res. 2009;83:74-78.

5. Aithal HP, Pratap AK, Singh GR. Clinical effects of epidurally administered ketamine and xylazine in goats. Small Ruminant Res. 1997;24(1):55-64.

6. DeRossi R, Junqueira AL, Beretta MP. Analgesic and systemic effects of ketamine, xylazine, and lidocaine after subarachnoid administration in goats. Am JVet Res. 2003;64(1):51-56.

7. Kinjavdekar P, Singh GR, Amarpal, Aithal HP, Pawde AM. Clinicophysiological effects of spinally administered ketamine and its combination with xylazine and medetomidine in healthy goats. Vet Res Commun. 2007;31(7):847-861.

8. Singh K, Kinjavdekar P, Amarpal, et al. Effects of epidural ketamine-xylazine combination on the clinicophysiological and haematobiochemical parameters of uraemic and healthy goats. Vet Res Commun. 2007;31(2):133-142.

9. Aithal HP, Amarpal, Kinjavdekar P, Pawde AM, Pratap K. Analgesic and cardiopulmonary effects of intrathecally administered romifidine or romifidine and ketamine in goats (Capra hircus). J S Afr Vet Assoc. 2001;72(2):84-91.
10. Derossi R, Junqueira AL, Lopes RA, Beretta MP. Use of ketamine or lidocaine or in combination for subarachnoid analgesia in goats. Small Ruminant Res. 2005;59(1):95-101.

11. Cable CS, Peery K, Fubini SL. Radical mastectomy in 20 ruminants. Vet Surg. 2004;33(3):263-266.

12. Fubini SL, Ducharme NG. Farm Animal Surgery. Elsevier, USA; 2004.

13. Radostits OM, Gay CC, Hinchcliff KW, Constable PD. Veterinary Medicine - A Textbook of the Diseases of Cattle, Horses, Sheep, Pigs, and Goats. 10th ed. Philadelphia:Saunders, USA; 2007.

14. El-Maghraby HM. Comparison of two surgical techniques for mastectomy of goats. Small Rumin Res. 2001;40(3):215-221.

15. Galatos AD. Anesthesia and analgesia in sheep and goats. Vet Clin North Am Food Anim Pract. 2011;27(1):47-59.

16. Reich DL, Silvay G. Ketamine: an update on the first twenty-five years of clinical experience. Can J Anaesth. 1989;36(2):186-197.

17. Morishima HO, Pedersen H, Finster M, et al. Toxicity of lidocaine in adult, newborn, and fetal sheep. Anesthesiology. 1981;55(1):57-61.

18. Hodgson PS, Neal JM, Pollock JE, Liu SS. The neurotoxicity of drugs given intrathecally (spinal). Anesth Analg. 1999;88(4):797-809.

19. Malinovsky JM, Pinaud M. Neurotoxicité des agents administrés par voie intrathécale. Ann Fr Anesth Reanim. 1996;15(5):647-658. French.

20. Islas JA, Astorga J, Laredo M. Epidural ketamine for control of postoperative pain. Anesth Analg. 1985;64(12):1161-1162.

21. Kawana Y, Sato H, Shimada H, et al. Epidural ketamine for postoperative pain relief after gynecologic operations: a doubleblind study and comparison with epidural morphine. Anesth Analg. 1987;66(8):735-738.
Veterinary Medicine: Research and Reports

\section{Publish your work in this journal}

Veterinary Medicine: Research and Reports is an international, peer-reviewed, open access journal publishing original research, case reports, editorials, reviews and commentaries on all areas of veterinary medicine. The manuscript management system is completely online and includes a very quick and fair peer-review system.

\section{Dovepress}

Visit http://www.dovepress.com/testimonials.php to read real quotes from published authors. 